\title{
Strategic Research on Accurate Marketing to Enhance Consumer Experience of Social Media Users
}

\author{
${ }^{1}$ Hong Jin \\ Jiangxi Normal University \\ Jiangxi, China \\ 342944219@.qq.com
}

\author{
${ }^{2}$ Chenchen Chi \\ Jiangxi Normal University \\ Jiangxi, China \\ 1139281226@qq.com
}

\author{
${ }^{3}$ Xingyu Gao \\ Jiangxi Normal University \\ Jiangxi, China \\ 525095256@qq.com
}

\begin{abstract}
With the rapid development of information technology, consumers are more active and pay more attention to consumption experience (such as interaction, participation and individuation). The traditional marketing modes gradually evolved into precision marketing, which has the characteristics of precision, efficiency and individuation. With the development of mobile network environment, precision marketing has become a new research focus in the academic circles under the mobile social media environment. "WeChat" is one of the most popular mobile social media in China nowadays; it has relatively strong universality as the research platform. This study summarized the domestic and foreign scholars' research of consumer experience, precision marketing and mobile social media. Aiming at improve the consumer purchasing experience, we put forward suggestions to improve the precision marketing of e-commerce enterprises from the perspective of consumers. These suggestions mainly focus on four aspects: accurate information transmission, platform construction, customer relationship management and brand extension.
\end{abstract}

Keywords-Consumer experience; Precision marketing; Mobile social media platform; WeChat

\section{INTRODUCTION}

The mobile Internet has caused consumers to make great changes in information collection, consumption concepts and decision-driven driving. In the competition to win user attention, improve consumer satisfaction and brand loyalty, every subtle change of consumers will affect their Purchase behavior and brand preferences. Extending to the enterprise level means that consumer driven consumption has become the main front of enterprise marketing, namely how to use mobile Internet thinking to reconstruct enterprise marketing value chain, the use of the Internet irreplaceable information integration and interpersonal communication functions for consumers to create the best consumer experience.

Through the research and analysis of the current mobile social media platform, this study selected the representative mobile Social Media Platform of "WeChat". Based on the current trend of marketing accuracy, this paper discusses how e-commerce enterprises do to attract consumers' participation, improve the efficiency of consumer decision making and solve consumers' after selling problems so as to enhance consumers' consumption experience. And try to integrate artificial intelligence technology with enterprise marketing strategy on the mobile social media platform efficiently, and then provide reference for e-commerce companies to improve consumers' shopping experience.

\section{LITERATURE REVIEW}

\section{A. Consumer Experience}

The consumer experience, also known as the user experience, refers to the feeling and understanding of a person when using the product or enjoying the service.

Since different scholars study consumption experience from different perspectives, they also have different views on the constituent dimensions of consumption experience. The main viewpoints include Holbrook's consumer experience metatheory, Csikszentmihalyi's the flow experience theory, Schmidt's Strategic Experience Module Theory and the experience two factor theory of Joseph Pine and James $\mathrm{H}$. Gilmore. The "dualism of experience": Many scholars believe that the consumer experience comes from direct or indirect interaction between consumers and products or services. They advocate two ways to divide the consumer experience: functional experience and hedonism experience. The "heart flow experience" theory: the concept of "heart flow experience" was first proposed by Csikszentmihalyi in 1960, "heart flow" is a feeling of completely investing one's mental strength in a certain activity. When heart flow comes into being, one will feel highly excited and full at the same time [1]. On the basis of the original definition, Novak and Thomas summarized the characteristics of the state of flow experience into three types of factors: conditional factors, experiential factors and outcome factors. The two important characteristics of the flow experience state are: the complete immersion in an activity and the pleasure of being able to get pleasure from the activity [2]; the strategic experience module: Schmidt 
according to the different functional modules of the brain, the customer experience is divided into five categories: senses, emotions, thoughts, actions, and connections, and they are seen as strategic experience modules. The tactical implementation tools used for these five experiences are called "experience providers" [3]; "experience two-factor theory": The experience is a good feeling in the mind when the customer reaches a certain level of emotion, physical strength, intelligence and even spirit [4].

\section{B. Precision Marketing}

Precision marketing is based on accurate positioning, relying on modern information technology to establish a personalized customer communication service system, to achieve a measurable low cost expansion of the enterprise. It is one of the core viewpoints in the concept of network marketing.

As an innovative marketing method, precision marketing is a research direction that is constantly updated by academic circles at any time; it has achieved relatively matured research results. American marketing scientist Lester Wunderman first proposed the concept of "direct marketing" in 1967; in 1999, he further proposed precision marketing. In 2005, Philip Kotler, the father of modern marketing, systematically proposed the concept of precision marketing. Jeff Zabin defines in its "Precision Marketing" that precision marketing is to send the right information to the right customer through the right channel at the right time, so as to truly influence the target customer's purchase decision and promote the marketing goal effectively achieved [5]. Precision marketing is a product of environmental change; it is affected by changes in science and technology, social environment and competitive market. It has been gradually improved and transformed [6]. The definition of precision marketing has emphasized the adoption of differentiated marketing strategies and communication strategies since 2010 , that is, on the basis of identifying and segmenting the target customers, the modern advanced information technology is used to set up personalized consumption scenes for consumers, so as to achieve the communication effect of low cost and high efficiency.

\section{Mobile Social Media Marketing}

Mobile social media marketing is a way to use social networks, online communities, blogs, encyclopedias or other Internet collaboration platforms to disseminate and publish information, thus completing marketing, public relations processing and customer relationship maintenance and development. Social media marketing has always existed and gradually shifted to the mobile side, from 2010 to now, mobile social tools represented by WeChat have gradually developed into the main positions of enterprise marketing.

With the development of mobile social media, future mobile social media content marketing will be more matured. Content marketing will become an indispensable part of the future enterprise marketing strategy [7]. In the development of the mobile internet era, the scene will become the core element of marketing [8]. With the advent of the Internet era, especially the rise of mobile Internet, time and space have been expanded infinitely, and we are always in vivid real scenes and virtual scenes. It can be said that the media, especially mobile media, have greatly enriched and activated the marketing scene, accelerated the interaction between the real and virtual scene, it would create more marketing imagination space for us. The new idea of developing precision marketing under mobile social media is to "combine information technology to improve information redundancy." Detect information every moment and deliver valid information to consumers. The second is " online and offline, the traditional mode is combined with the mobile terminal to enrich the audience." Expanding the target audience; third, the "clear target market segmentation" accurately selects the target market [9].

\section{ANALYSIS OF WECHAT MARKETING MODEL}

After micro-blog marketing, WeChat marketing has quickly become a hot marketing tool in the enterprise marketing process, relying on its strong user stickiness and precise target customer positioning. By referring to the existing marketing model and summarizing the practice case of enterprise WeChat marketing, it is found that the existing marketing models mainly include the following:

\section{A. High Exposure Model}

The first type is to increase the exposure rate of enterprise information[10]. Firstly, disseminating grassroots advertise. Enterprises use the functions of circle of friends, floating bottles and so on to help enterprises obtain user information and select locations with high traffic to expose enterprise product information. Secondly, by establishing the official WeChat public number, the enterprise launched marketing activities to attract individual users paying attention to the enterprise information actively. Enterprises improve brand exposure by communicating with unfamiliar users.

\section{B. O2O Membership Model [10]}

Since the appearance of WeChat scanning QR code, "QR code" has become a tool for O2O marketing. WeChat users identify and update the QR code by scanning, adding friends and paying attention to the enterprise account. Therefore, in the field of marketing, users can obtain an electronic membership card by scanning the exclusive QR code provided by the enterprise; the membership card could provide the member discount, special service and so on.

\section{Social Sharing Model [10]}

With the development of WeChat's social function, it has become a trend for users to "brush circle of friends" in fragmented time. In the circle of friends, the user's personal information is fully displayed, and the WeChat circle of friends also provides a natural marketing platform for enterprise marketing. Through WeChat's circle of friends, corporate brand information will be spread like a virus, which effectively improves the brand's spread and thus promotes word-of-mouth marketing. 


\section{Interactive Marketing Model [10]}

The function of social sharing in the circle of friends has greatly demonstrated the value of WeChat in the field of marketing. The emergence of WeChat public platform is the icing on the cake and further refines the value. According to their own interests and needs, WeChat users pay attention to the WeChat public platform (including the subscription number and service number), obtain relevant information and consulting services actively. Enterprises promote public numbers to WeChat users and attract them to subscribe. Then, the WeChat public platform subdivides the subscribing users through relevant statistical analysis of data, and transmits messages of interest to the targeted users.

\section{MANAGEMENT ENLIGHTENMENT}

Based on the analysis of the three parts above, the strategy based on the precise marketing on the WeChat platform to enhance the consumer experience is proposed as follows:

\section{A. Transmit Information Accurately}

Not every Consumer knows what they need in every moment. It's a good idea to divide consumers into two types: with clear goals and fuzzy goals. The target specific consumers will search for the target independently. For such consumers, the consumer database can be established according to the search keywords and the corresponding demand information can be transmitted in time; the target fuzzy consumers mainly search for the target through the method of classified search. Such consumer demand information is relatively vague; therefore, the platform can first define the user's portrait according to its search keywords, and then guide consumers to create topics independently. The related topics can be shared; the platform is responsible for the operation and maintenance. This can not only penetrate and satisfy more consumers' needs, but also enhance platform stickiness.

\section{B. Ensure Information Feasibility}

For brands: Improve the technical support for information exchange in the online shopping process; Broaden the channels for suppliers to display product information and for consumers to obtain product information, such as video demonstrations, $3 \mathrm{D}$ virtual simulation experience; The network distribution of brands should be open and transparent. Consumers have the right to inspect the qualifications of network distributors, specifically the agency information of each network distributor of each brand can be clearly publicized on the e-commerce platform, and severely crack down on the counterfeiters; Improve the commodity review system. Establish a censorship system to release the commodity information, reduce the confusion of "defective" goods to consumers.

For e-commerce platform: Raise the threshold of entry for platform merchants; Establish a sound credit rating system to provide consumers with correct public opinion guidance; Guide the identity of platform "enterprises themselves platform - consumer" interest community relations.

\section{Increase the Interaction Frequency}

For brands: Learn from social media membership promotion mechanism. Senior members can enjoy more brand privileges, such as participation in product design and entry experience; establish an official brand portal on the mobile social media platform. By passing on the brand design concept, consumers are attracted to design their own brand products, and the brand is responsible for its promotion. In this way, the interaction between brands and consumers can be realized and the personalized needs of consumers can be met.

For the e-commerce platform: Reduce irrelevant information transmit and increase user-defined items; Collective activities can also be launched on WeChat, such as voting for your favorite sports shoes brand; By expanding offline stores and other means, consumers can also improve their sense of experience.

\section{Guide Consumption Sharing}

For e-commerce platforms: Firstly, use the record-able and traceable nature of social network data to identify the type of consumer, whether it is transaction or common relation type. For transaction type customers, it should start with economic incentives, such as coupons, bargaining and other means; for common relation type customers, use emotional stimulation, show concern, and retain customer's hearts, such as consumer annual reports that focus on humanistic care. Finally, focus on three-dimensional social networks: enterprise, customer, relatives and friends of the customer. The tangible nature of social networks makes the explicit behavior of customers take these three factors into account. The e-commerce platform can motivate consumers by analyzing the consumer's personalized characteristics, such as allowing consumers to test their own colors through VR technology, and analyzing the most suitable lipstick color.

\section{E. Rapid Response and Effective Communication}

Compared with before selling communication, the enterprise's after selling communication ability has a greater impact on the enterprise's image. Through mobile social media, there will be positive word-of-mouth and negative word-ofmouth in the marketing way that radiates to the consumer's personal social circle. Positive word-of-mouth spreads information that is beneficial to the company and helps to establish a positive image of the brand. However, when consumers complained, that is, the negative word-of-mouth appears. The merchant should communicate with the consumer to find out and understand in which part of the product makes the problem occurs, and properly handle it to improve the satisfaction of these consumers. When the influence of negative word-of-mouth is larger, enterprises should adopt positive public relations methods to reduce the probability of disseminating negative information. 


\section{F. Strengthen the Relationship with Consumers}

The value of loyal customers is far greater than that of new customers. Therefore, it is very important for enterprises to strengthen the relationship with consumers and improve their loyalty. Enterprises can establish more convenient communication channels, such as WeChat public number, to quickly respond to market and consumer demands; improve the after selling service system. A perfect after selling service system can greatly improve consumer satisfaction and loyalty; In addition, the relationship between the platform and consumers can also be narrowed by improving the consumer database, clarifying consumer portraits and providing personalized services for them.

\section{G. Expand Offline Store}

The offline stores have the authenticity that the online stores do not have, which could help to improve the consumer's consumption experience. E-Commerce enterprises can create consumption scenes for consumers by building offline theme stores to provide an immersive consumption experience; In addition, the use of artificial intelligence technology to develop offline - online integration is conducive to the healthy development of the enterprise industrial chain.

\section{CONCLUSION}

Precision marketing can help brand improve marketing effect in many aspects, which is a new direction of marketing development. Enterprises can adopt the method of transmitting information accurately to promote consumers' purchase; increase consumer trust by verifying the validity of information; adopt membership system to increase consumer loyalty; use personalized means to stimulate consumer sharing; pay close attention to consumer dynamics in real time, always take a positive attitude to respond to consumer feedback, and strengthen the relationship between enterprises and consumers; pay attention to the laying of offline stores in order to enhance consumer experience and promote purchase. The research in this paper could help e-commerce platform bring consumers a better consumer experience. By exploring how to better combine new things with traditional things under the inevitable trend of the times, we can effectively enhance consumers' experience in senses, emotions, thinking and actions.

This paper proposes corresponding marketing suggestions for the e-commerce enterprises by referring to and integrating the theoretical research of the outstanding predecessors and the author's own understanding. However, due to the limitations of the author's research level, there are many areas to be further studied in this paper, such as further exploring the effectiveness of strategies from the perspective of consumers by means of data analysis.

\section{ACKNOWLEDGMENT}

This study is supported by Jiangxi Universities Humanities and Social Sciences Research on Young Fund (GL17115).

\section{REFERENCES}

[1] Csikszentmihalyi Mihaly, Finding Flow: The Psychology of Engagement with Everyday Life: Basic Books, 1997.

[2] Ghani, Jawaid A, and S. P. Deshpande. Task Characteristics and the Experience of Optimal Flow in Human-Computer Interaction. J. Journal of Psychology, 1994, pp. 381-391.

[3] Schmitt B, Experiential Marketing: How to Get Customers to Sense, Feel, Think, Act, Relate To Tour Company and Brands. New York: The Free Press, 1999, pp.271.

[4] Pine B J, Gilmore J H. Welcome to the experience economy. J. Harvard Business Review, 1998, pp.97-105.

[5] Jeff Zabin, Gresh Brebach, Precision Marketing: The New Rules for Attracting, Retaining, and Leveraging Profitable Customers: John Wiley \&Sons Inc. 2008

[6] Jun Wang, Guisong Chen, Jiahua Tian. A Probe into Precision Marketing Theory. J. China Collective Economy, 2009, pp.70-71. (In Chinese)

[7] Meimei Zhao. Research on Mobile Social Media Content Marketing Strategy in The Era of Mobile Internet. J. Foreign Trade, 2017, pp.121123. (In Chinese)

[8] Yue Hao. Application Status and Future of Scenes in Mobile Social Media. J. Communication and Copyright, 2018, pp.1-3. (In Chinese)

[9] Wei Xu, Shaorong Sun. Summary of Precision Marketing Research and New Development under Mobile Social Media. J. China Forestry Economics, 2018, pp.102-107. (In Chinese)

[10] Li Zhang. Precision Marketing Research of WeChat in the Background of Social Media Marketing. Jilin University of Finance and Economics, 2014. (In Chinese) 